\title{
Housing issue in shrinking Russian cities: mapping the reality
}

\author{
Elena BATUNOVA ${ }^{\mathrm{a}}$, Maria GUNKO ${ }^{\mathrm{b} *}$ \\ ${ }^{a}$ Department of Architecture and Urban Studies, Politecnico di Milano, elena.batunova@polimi.it \\ ${ }^{b}$ Institute of Geography, Russian Academy of Sciences, msgunko@igras.ru \\ * Corresponding author
}

Keywords: mapping cities, urban shrinkage, housing, Russia

\begin{abstract}
:
In Russia, housing issue has been remaining one of the most important political concerns since the beginning of the 20th century. In the recent political discourse, it is associated mainly with the need to provide new housing area and the improvement of housing conditions regardless of the difference in the development of regions or cities. However, the fact that over 70\% of Russia's cities shrink (Batunova and Gunko, 2018) requires developing specific approaches to housing policy's formulation within depopulating territories.

The phenomenon of urban shrinkage is generally understood as population decline which results in physical urban infrastructure surplus \& degradation. Dilapidated or abandoned houses become the most evident sign of a city's decline and one of the most important challenges for the local authorities. However, most examples known from the existing literature come from the countries of Western Europe and the US, where economic factors are the main drivers of urban depopulation. The real estate market reacts to the population decline by falling prices (Follain, 2010), which worsens the economic situation in the city and leads to a vicious circle of economic/population decline.
\end{abstract}

Less is known about what happens with the housing stock of, in words of J. B. Hollander (2018), 'atypical shrinking cities', where demographic aspects are the primary causes of depopulation: the excess of mortality over fertility and ageing. Hollander applied the term 'atypical' to Japanese shrinking cities, but in Russia, urban shrinkage is also foremost a result of demographic change (Karachurina, 2013). International migration to Russia does not compensate natural population decline, while the national policies are oriented towards promoting growth in large metropolitan areas (Kinossian, 2013) which intensifies internal migration flows from cities which are not the foci of national development. Consequently, for many Russian cities, especially small peripheral ones, urban shrinkage is an inevitable process.

Russian shrinking cities face or will face difficulties with managing housing. First, a large part of the existing housing stock in Russia was built in a short period after WWII that means simultaneous dilapidation of many buildings. Moreover, housing conditions are worsening very fast due to the absence of its maintenance, renovation and reconstruction (United Nations, 2004) and in shrinking cities with shrinking budgets, the situation is much more challenging. Second, local authorities often do not recognise the scale of the problem - there are no monitoring systems, registry maintenance or mapping of abandoned or degraded housing, which means no awareness about the current situation. Third, a high share of privately-owned housing, which according to the Russian Federal Statistic Service (Rosstat) was $90.5 \%$ in 2017 , limits the municipalities' opportunities to monitor and manage housing stock. This is especially true concerning apartment buildings, where abandonment of one apartment is not immediately evident and searching for the dwellings' owners is a complicated task. Fourth, small depopulating municipalities in Russia do not have financial and organisational recourses for the forming of monitoring system: often they use obsolete topographic maps, do not have skilled specialists to actualise and create maps etc.

Against this background our research questions are as follows: What happens to housing stock in shrinking Russian cities? What are the preconditions (tools, regulations) for managing housing stock in shrinking Russian cities: official discourse of urban shrinkage, reaction to the transformation of housing demand-supply, main approaches to manage housing excess?

To answer the first question, we turned to cartographic methods of research. The study of housing in selected shrinking cities (Vorkuta, Komi Republic and Apatity, Murmansk region) was based on visualization of statistical information, crowdsourcing of spatial data and visual decoding of remote sensing data, based on the theory of decryption features for the recognition of objects. To interpret high-resolution images direct (geometry, brightness, and structural) and indirect signs were used. The utilized data includes images from WorldView 1/2/3, QuickBird, GeoEye, which are published on the web mapping services of Yandex.Maps, GoogleMaps, BingMaps (Microsoft), ArcGIS.Imagery (ESRI), Roscosmos Geoportal. Maps of scale 1:10000 and 1:100000 became cartographic data sources. For comparison of data on separate structures regional statistical data of BTI (Technical Inventory Bureau) were used, to identify and verify abandoned houses and apartments field observations were also conducted. The main stage of work was the logical organization of data and the development of the geodatabase structure for the future geoinformation analytical system. All presented information is divided into two types: spatial datasets of different geometry (layers) and tabular data with thematic attribute information. This integrated approach to the state of the urban environment has been implemented for the first 
time in Russia and, supplemented by the capabilities of automatic spatial analysis in GIS, will identify the most 'acute' issues for territorial planning and housing management in shrinking cities. In addition, a series of maps were created visualizing housing features and condition which were presented to the local administrations of the case study cities.

To answer the second question, we conducted an analysis of the local strategic, planning and policy document as well as interviews with the local stakeholders. The results vary in two cities. While local planning and policy in the realm of housing in Vorkuta are adequate to the identifies housing issues, in Apatity local development plans still serve land provision for the future 'dreamt' housing construction, needs of which are calculated based on over-optimistic demographic projections that do not consider the real factors influencing population development.

\section{Acknowledgements:}

The research was supported by the Ministry for Science of the Russian Federation, grant \# MK-4946.2018.6

\section{References:}

Batunova E. and Gunko M. (2018). Urban shrinkage: an unspoken challenge of spatial planning in Russian small and medium-sized cities. European Planning Studies, 26(8), 1580-1597.

Follain, J. R. (2010). A Study of Real Estate Markets in Declining Cities. Special report. Research Institute for Housing America.

Hollander, J.B. (2018). A Research Agenda for Shrinking Cities. Elgar Research Agendas.

Karachurina, L. (2013). The demographical transformations of cities in post-Soviet Russia [Demograficheskie transformatsii gorodov post-sovetskoy Rossii]. Regionalnie issledovaniya, 41 (3), 23-36.

Kinossian, N. (2013). Stuck in transition: Russian regional planning policy between spatial polarization and equalization. Eurasian Geography and Economics, 54(5-6), 611-629.

Rosstat. Russian Federal State Statistics Service website. Available at: http://www.gks.ru/. (Accessed 12 December 2018).

United Nations (2004). Country profiles on the housing sector. Russian Federation. Geneva, Switzerland. 